\title{
Fat-Free Mass Index for Evaluating the Nutritional Status and Disease Severity in COPD
}

\author{
Yuwen Luo MSc, Luqian Zhou PhD, Yun Li MSc, Songwen Guo MSc, Xiuxia Li MSc, \\ Jingjing Zheng MSc, Zhe Zhu MSc, Yitai Chen MSc, Yuxia Huang MSc, Rui Chen PhD, and \\ Xin Chen PhD
}

BACKGROUND: Despite the high prevalence of weight loss in subjects with COPD, the 2011 COPD management guidelines do not include an index measuring nutritional status. Fat-free mass index (FFMI) can accurately determine the nutritional status of subjects and may be closely correlated with COPD severity. We aimed to determine the nutritional status evaluated by FFMI according to the 2011 Global Initiative for Chronic Obstructive Lung Disease (GOLD) levels in stable subjects with COPD and the association between nutritional status and respiratory symptoms, exercise capacity, and respiratory muscle function. METHODS: We included 235 stable subjects with COPD in this cross-sectional study. All of the subjects were divided into the 2011 GOLD Groups A, B, C, and D. FFMI (measured by bioelectrical impedance), spirometry (FEV , percent-of-predicted $\mathrm{FEV}_{1}$, and $\mathrm{FEV}_{1} / \mathrm{FVC}$ ), respiratory muscle function (peak inspiratory and peak expiratory pressures), exercise capacity (6-min walk distance), and dyspnea severity (Modified Medical Research Council dyspnea scale) were measured and compared between the GOLD groups. RESULTS: Malnutrition was identified in $48.5 \%$ of subjects and most prevalent in Group D (Group A: 41\%, Group B: 41\%, Group C: 31\%, and Group D: 62\%). FFMI was significantly lower in Group D $(P<.001)$, with both sexes considered malnourished. Low FFMI significantly correlated with frequent exacerbation, older age, decreased pulmonary function, 6-min walk distance, peak inspiratory pressure, and worsened dyspnea. FFMI was significantly lower in the emphysemadominant phenotype and mixed phenotype compared with the normal phenotype and airwaydominant phenotype. A stepwise multiple linear regression analysis identified peak inspiratory pressures and older age as independent predictors of FFMI. CONCLUSIONS: Malnutrition is highly prevalent in all COPD groups, particularly in Group D subjects, who warrant special attention for nutritional intervention and pulmonary rehabilitation. FFMI significantly correlated with exercise capacity, dyspnea, respiratory muscle function, and pulmonary function and may be a useful predictor of COPD severity. Key words: chronic obstructive pulmonary disease; epidemiology; free fat mass index; malnutrition; pulmonary function; prognosis. [Respir Care 2016;61(5):680-688. (C) 2016 Daedalus Enterprises]

Introduction

COPD is is a common chronic respiratory disease characterized by persistent air flow limitation that primarily

\footnotetext{
Mr YW Luo, Mr Y Li, Mr SW Guo, Ms XX Li, Ms JJ Zheng, Mr Z Zhu, Mr YT Chen, Ms YX Huang, and Dr X Chen are affiliated with the Department of Respiratory Medicine, Zhujiang Hospital, Southern Medical University, Guangzhou 510282, China. Dr LQ Zhou is affiliated with the State Key Laboratory of Respiratory Disease, Guangzhou Institute of Respiratory Disease, Guangzhou Medical University, Guangzhou 510120, China. Dr R Chen
}

affects the lung and causes systemic complications. ${ }^{1}$ COPD exacerbation and comorbidities contribute to the overall severity of disease in individual subjects. COPD is predicted to be the seventh leading cause of disease leading to disability worldwide by 2030 from its current position at twelfth. ${ }^{1}$ In $2011,{ }^{2}$ the Global Initiative for Chronic Ob-

\footnotetext{
is affiliated with the Department of Respiratory Diseases, SUN Yat-sen Memorial Hospital, SUN Yat-sen University, Guangzhou 510120, China.

Mr YW Luo, Dr LQ Zhou, and Mr Y Li are co-first authors.
} 
structive Lung Disease (GOLD) proposed a comprehensive system, including multiple variables such as symptoms, severity of air flow limitation, and history of exacerbation, for the diagnosis and management of COPD that better reflects COPD severity than previous indices measuring air flow limitation. However, several other variables, including exercise tolerance, weight loss, low fatfree mass index (FFMI), and respiratory failure, place subjects at an increased risk for mortality.

COPD can cause significant systemic effects, such as weight loss and muscle dysfunction. ${ }^{3}$ In several survival studies, ${ }^{4-6}$ weight loss was particularly prevalent in subjects with COPD; this trend was closely correlated with exercise capacity limitation, decreased quality of life, increased frequency of exacerbations, and mortality. ${ }^{78}$ The weight loss in subjects with COPD has been ascribed to alterations in caloric intake, basal metabolic rate, and body composition $^{9-11}$ and increased inflammatory mediators. ${ }^{12}$ Currently, the nutritional status of subjects with COPD is primarily evaluated using body mass index (BMI). ${ }^{1}$ However, alterations in body composition can occur in COPD in the absence of clinically important weight loss. ${ }^{9}$ Body mass comprises the fat mass and the free fat mass, which includes highly metabolically active organs, especially the skeletal muscle. Some studies show that FFMI is more closely correlated with COPD mortality and may better reflect the muscle mass compared with BMI. ${ }^{13-15}$ FFMI could negatively affect other indices used to evaluate the COPD severity, such as the lung function grade, frequency of exacerbation, respiratory muscle strength, health-related quality of life, dyspnea, and exercise capacity.7,8,13,14 Ischaki et $\mathrm{al}^{14}$ investigated nutritional status in subjects with clinically stable COPD equally classified into the 5 stages according to $\mathrm{FEV}_{1}$ and showed that FFMI was significantly correlated with air flow limitation and obstruction compared with BMI. A study by Steuten et al ${ }^{16}$ showed that the incidence of low FFMI increased as the pulmonary function worsened. The 2011 GOLD classification is recognized to better reflect COPD severity; however, the distribution of FFMI among the 2011 GOLD groups remains

\footnotetext{
This work was supported by Guangdong Provincial Science and Technology Project 2013B022000072 and 2011B080701062, Guangdong Natural Science Foundation Project S2012010008623, and Guangzhou Municipal Science and Technology Project 201507020033. The authors have disclosed no conflicts of interest.
}

Correspondence: Xin Chen PhD, Department of Respiratory Medicine, Zhujiang Hospital, Southern Medical University, Guangzhou 510282, China. E-mail: chen_xin1020@ hotmail.com. Rui Chen PhD, Department of Respiratory Diseases, SUN Yat-sen Memorial Hospital, SUN Yat-sen University, Guangzhou 510120, China. E-mail: gzchenrui@163.com.

DOI: $10.4187 /$ respcare. 04358

\section{QUICK LOOK}

\section{Current knowledge}

The 2011 Global Initiative for Chronic Obstructive Lung Disease (GOLD) proposed a comprehensive system that better reflects COPD severity than previous indices measuring air flow limitation. Fat-free mass index (FFMI) can accurately determine the nutritional status of subjects and may be closely correlated with COPD severity. However, the distribution of FFMI among the 2011 GOLD groups remains uncertain.

\section{What this paper contributes to our knowledge}

Malnutrition is prevalent in all COPD groups, especially in subjects with high risk and more symptoms as described in the 2011 GOLD guidelines. Therefore, this study highlights the need to focus on nutritional intervention and pulmonary rehabilitation in this patient group. FFMI is significantly correlated with exercise capacity, dyspnea, respiratory muscle function, and $\mathrm{FEV}_{1}$ and could be used to predict COPD severity.

uncertain. The present study used FFMI to analyze the nutritional status of stable subjects with COPD in different GOLD groups to determine the relationship between FFMI and respiratory symptoms, exercise capacity, and respiratory muscle function.

\section{Methods}

\section{Subjects}

The nutritional status of subjects with COPD was investigated using a cross-sectional study, and the indices correlated with COPD were recorded. The study population comprised subjects with COPD examined at the outpatient clinic of Zhujiang Hospital, Southern Medical University, between June 2013 and September 2014. Subjects were included according to the following criteria: age $\geq 18 \mathrm{y}$, diagnosis of COPD according to pulmonary function tests, and clinically stable COPD. Subjects with exacerbation within the previous 2 months or with serious organ failure, malignant tumor, or metabolic disease and uncooperative subjects were excluded. The COPD severity was assessed according to the 2011 GOLD guidelines using the modified British Medical Research Council dyspnea scale (MMRC), $\mathrm{FEV}_{1}$, and frequency of exacerbations in the last year. The 4 groups were as follows: Group A, low risk, fewer symptoms; Group B, low risk, more symptoms; Group C, high risk, fewer symptoms; Group D, high risk, more symptoms. ${ }^{1}$ 


\section{Pulmonary Function and Respiratory Muscle Function Testing}

Pulmonary function was measured using a spirometer (PonyFX 229, Cosmed, Rome, Italy) that was calibrated daily. ${ }^{17}$ The $\mathrm{FEV}_{1}$, percent-of-predicted $\mathrm{FVC}$, and $\mathrm{FEV}_{1} / \mathrm{FVC}$ were measured before and after the bronchodilator test.

During the bronchodilator test, subjects were instructed to inhale $400 \mu \mathrm{g}$ of salbutamol using a handheld spirometer. Subjects were instructed not to use any inhaled medications on the day of pulmonary function assessment or within $6 \mathrm{~h}$ before testing. The highest $\mathrm{FEV}_{1}$ and FVC values of at least 3 acceptable spirometric maneuvers and the largest $\mathrm{FEV}_{1} / \mathrm{FVC}$ from a technically acceptable curve were used for analysis. Respiratory muscle function was determined based on the maximal inspiratory pressure $\left(\mathrm{P}_{\text {Imax }}\right)$ and maximal expiratory pressure $\left(\mathrm{P}_{\mathrm{Emax}}\right)$ using the largest value of 3 technically correct maneuvers according to the American Thoracic Society/European Respiratory Society statement on respiratory muscle testing. ${ }^{18}$ The lower limit of normal $\mathrm{P}_{\text {Imax }}$ measured by a digital manometer (AZ-8205, AZ Instrument, Taichung City, Taiwan) was $75 \mathrm{~cm} \mathrm{H}_{2} \mathrm{O}$ in men and $50 \mathrm{~cm} \mathrm{H}_{2} \mathrm{O}$ in women. ${ }^{19}$ The lower limit of normal $\mathrm{P}_{\text {Emax }}$ was $100 \mathrm{~cm} \mathrm{H}_{2} \mathrm{O}$ in men and $80 \mathrm{~cm} \mathrm{H}_{2} \mathrm{O}$ in women.

\section{Fat-Free Mass Index Test}

FFMI was measured by multifrequency and 8 -spot contact bioelectrical impedance in $\mathrm{kg} / \mathrm{m}^{2}$ according to the equation, FFMI $=$ fat-free mass $/$ height $^{2}$. A low FFMI was defined as FFMI $\leq 15 \mathrm{~kg} / \mathrm{m}^{2}$ in women and FFMI $\leq 16$ $\mathrm{kg} / \mathrm{m}^{2}$ in men, as reported previously. ${ }^{20,21}$

\section{Dyspnea}

MMRC was adopted to evaluate the severity of breathlessness. ${ }^{22}$ Subjects were categorized into 5 grades according to the dyspnea severity as follows: Grade 0 , subject experiences dyspnea only during strenuous exercise; Grade 1 , subject experiences dyspnea when moving briskly on level ground or walking up a slight incline; Grade 2, subject walks more slowly on level ground than age-matched individuals due to dyspnea or is forced to stop when walking at subject's own pace on level ground due to dyspnea; Grade 3, subject forced to stop due to dyspnea after walking approximately $100 \mathrm{~m}$ or after walking several minutes on level ground; and Grade 4, subject experiences severe dyspnea preventing the subject from leaving the house or dyspnea during routine activity, such as dressing or undressing.

\section{Exercise Capacity}

Exercise capacity was evaluated using the 6-min walking distance (6MWD) according to American Thoracic Society guidelines. ${ }^{23}$ Both the oxyhemoglobin saturation and heart rate were monitored by pulse oximetry. All tests were conducted by an experienced respiratory therapist, and the oxygen saturation was maintained $>90 \%$ during testing in all subjects. The largest value measured over 2 days was subjected to analysis.

\section{Computed Tomography Scans}

We used high-resolution computed tomography (CT) to quantify and calculate the percentage of low-attenuation area and section helical CT to quantify airway dimensions. ${ }^{24}$ Both scans were performed in a supine position using a 256-slice CT scanner (Brilliance iCT, Philips, Eindhoven, Netherlands)..$^{24}$ The percentage of low-attenuation area was calculated using a previously reported method, with $-960 \mathrm{HU}$ as the cut-off level. The dimensions of the right apical segmental bronchus were measured as described previously, and the percentage of wall area was used in the analyses. ${ }^{24}$

\section{COPD Phenotypes}

COPD can be classified into 4 groups according to the percentage of low-attenuation area and percentage of wall area. The 4 groups were: CT-normal (low percentage of low-attenuation area and low percentage of wall area), airway-dominant (low percentage of low-attenuation area and high percentage of wall area), emphysema-dominant (high percentage of low-attenuation area and low percentage of wall area), and mixed (high percentage of lowattenuation area and high percentage of wall area) phenotypes, respectively. ${ }^{25}$

\section{Ethical Approval}

The study protocol was reviewed by the appropriate ethics committee, and the study was performed in accordance with the ethical standards laid down in the 2000 Declaration of Helsinki. All persons gave their informed, written consent before study inclusion.

\section{Statistical Analysis}

The statistical analyses were performed using SPSS 13 (SPSS, Chicago, Illinois). Results are presented as the mean $\pm \mathrm{SD}$, unless stated otherwise, and proportional data are presented as percentages. Groups were compared using one-way analysis of variance as appropriate. Two groups were compared using the independent samples $t$ test. Rel- 
Table 1. Prevalence of Malnutrition of Subjects According to Fat-Free Mass Index and COPD Stage

\begin{tabular}{|c|c|c|c|c|c|c|c|c|}
\hline & \multicolumn{2}{|c|}{ Group A } & \multicolumn{2}{|c|}{ Group B } & \multicolumn{2}{|c|}{ Group C } & \multicolumn{2}{|c|}{ Group D } \\
\hline & $n$ & $\%$ & $n$ & $\%$ & $n$ & $\%$ & $n$ & $\%$ \\
\hline \multicolumn{9}{|c|}{ Normal FFMI } \\
\hline Male & 20 & 45.4 & 15 & 44.1 & 25 & 49.0 & 33 & 31.1 \\
\hline Female & 6 & 13.6 & 5 & 14.7 & 10 & 19.6 & 7 & 6.6 \\
\hline Total & 26 & 59.1 & 20 & 58.8 & 35 & 68.6 & 40 & 37.7 \\
\hline \multicolumn{9}{|c|}{ Malnutrition } \\
\hline Male & 14 & 31.8 & 11 & 32.4 & 15 & 29.4 & 51 & 48.1 \\
\hline Female & 4 & 9.1 & 3 & 8.8 & 1 & 2.0 & 15 & 14.2 \\
\hline Total & 18 & 40.9 & 14 & 41.2 & 16 & 31.4 & 66 & 62.3 \\
\hline
\end{tabular}

Malnutrition is defined as fat-free mass index $\leq 15 \mathrm{~kg} / \mathrm{m}^{2}$ in women and $\leq 16 \mathrm{~kg} / \mathrm{m}^{2}$ in men. FFMI $=$ fat-free mass index

Table 2. Correlation Analysis of Continuous Variables Associated With Fat-Free Mass Index

\begin{tabular}{lrc}
\hline \hline & $\mathrm{r}$ & $P$ \\
\hline Age & -0.27 & $<.001$ \\
\% Predicted FEV 1 & 0.17 & .01 \\
Exacerbations & -0.12 & .75 \\
6MWD & 0.26 & $<.001$ \\
MMRC & -0.21 & .02 \\
$\mathrm{P}_{\text {Imax }}$ & 0.32 & $<.001$ \\
$\mathrm{P}_{\text {Emax }}$ & 0.23 & $<.001$ \\
& & \\
MMRC = modified Medical Research Council dyspnea scale & \\
6MWD = 6-min walk distance & & \\
$\mathrm{P}_{\text {Imax }}=$ maximal inspiratory pressure & & \\
$\mathrm{P}_{\text {Emax }}=$ maximal expiratory pressure & & \\
\hline
\end{tabular}

evant indicators of COPD were assessed using Spearman correlation or Pearson correlation analysis. A multiple stepwise linear model including potential confounding factors was established to identify factors independently associated with FFMI. A $P$ value of $<.05$ was considered statistically significant.

\section{Results}

The clinical characteristics and GOLD classification of the subjects are shown in Table 1. Group D (45\%) was the largest of the groups, and Group B (14\%) was the smallest. There were more men than women in all GOLD groups.

Malnutrition was identified in $48.5 \%$ of subjects according to the FFMI, with Group D (62.3\%) comprising most of the malnourished subjects, followed by Group A (40.9\%), Group B (41.2\%), and Group C (31.4\%) in Table 2. FFMI was significantly decreased in Group D $(P<.001)$, and both men and women met the definition of malnutrition (men: $\leq 15.4 \pm 2.2 \mathrm{~kg} / \mathrm{m}^{2}$; women: $\leq 14.6 \pm 1.6 \mathrm{~kg} / \mathrm{m}^{2}$ ).
Table 3. Levels of Fat-Free Mass Index for Different COPD Phenotypes

\begin{tabular}{|c|c|c|c|c|c|}
\hline & \multicolumn{4}{|c|}{ Phenotypes } & \\
\hline & $\begin{array}{l}\text { CT- } \\
\text { Normal }\end{array}$ & $\begin{array}{l}\text { Airway- } \\
\text { Dominant }\end{array}$ & $\begin{array}{c}\text { Emphysema- } \\
\text { Dominant }\end{array}$ & Mixed & \\
\hline$n(\%)$ & $10(24.30)$ & $6(14.63)$ & $16(39)$ & $9(21.95)$ & \\
\hline FFMI, $\mathrm{kg} / \mathrm{m}^{2}$ & 17.46 & 17.65 & 15.32 & 15.22 & .01 \\
\hline $\begin{array}{l}\mathrm{CT}=\text { computed to } \\
\mathrm{FFMI}=\text { fat-free } \mathrm{m}\end{array}$ & $\begin{array}{l}\text { nography } \\
\text { ss index }\end{array}$ & & & & \\
\hline
\end{tabular}

The $\mathrm{FEV}_{1}, \mathrm{P}_{\mathrm{Imax}}$, and $\mathrm{P}_{\mathrm{Emax}}$ were decreased in Groups $\mathrm{C}$ and D. Group D showed the lowest 6MWD. The MMRC was significantly higher in Groups B and D than that in Groups A and D, as predicted.

FFMI was associated with increased age, frequency of exacerbation, 6MWD, MMRC, $\mathrm{P}_{\text {Imax }}, \mathrm{P}_{\mathrm{Emax}}$, and percentof-predicted $\mathrm{FEV}_{1}$, as shown in Table 3 and Figure 1. The mean FFMI among the variables by GOLD category is shown in Table 4. Among them, older age, more frequent exacerbation, deceased lung function, worsened dyspnea, decreased 6MWD, and decreased $\mathrm{P}_{\text {Imax }}$ were significantly correlated with a low FFMI. A stepwise multiple linear regression analysis identified $\mathrm{P}_{\mathrm{Imax}}$ and older age as independent predictors of FFMI (Table 5).

Based on the CT scan, 41 subjects with COPD were classified into the 4 phenotypes, with $10(24.30 \%)$ as CTnormal phenotype, $6(14.63 \%)$ as airway-dominant phenotype, 16 (39\%) as emphysema-dominant phenotype, and $9(21.95 \%)$ as mixed phenotype (Table 6).

\section{Discussion}

Using the FFMI, we observed a high incidence of malnutrition in every COPD group, especially in Group D, indicating that these subjects warrant special attention for nutritional intervention and pulmonary rehabilitation. FFMI was strongly correlated with the exercise capacity, dyspnea, respiratory muscle function, and $\mathrm{FEV}_{1}$ and could be a predictor of COPD severity.

An epidemiological investigation of 389 subjects with COPD at 39 clinical centers in the Netherlands found that the incidence of low FFMI was $27 \% .{ }^{26}$ Similarly, approximately $36 \%$ of subjects were malnourished in a nutritional analysis of 169 subjects with COPD conducted by Nordén et al. ${ }^{27}$ In our study, malnourishment was prevalent in subjects with stable COPD (48.5\%), with the largest incidence of malnourishment in Group D. The higher incidence of malnourishment observed in our study than in previous reports may reflect differences in the ethnicity of the subjects, since the subjects in our study were Asians, who often have smaller body frames than whites. ${ }^{28}$ Inter- 


\section{FAt-Free Mass IndeX IN COPD}
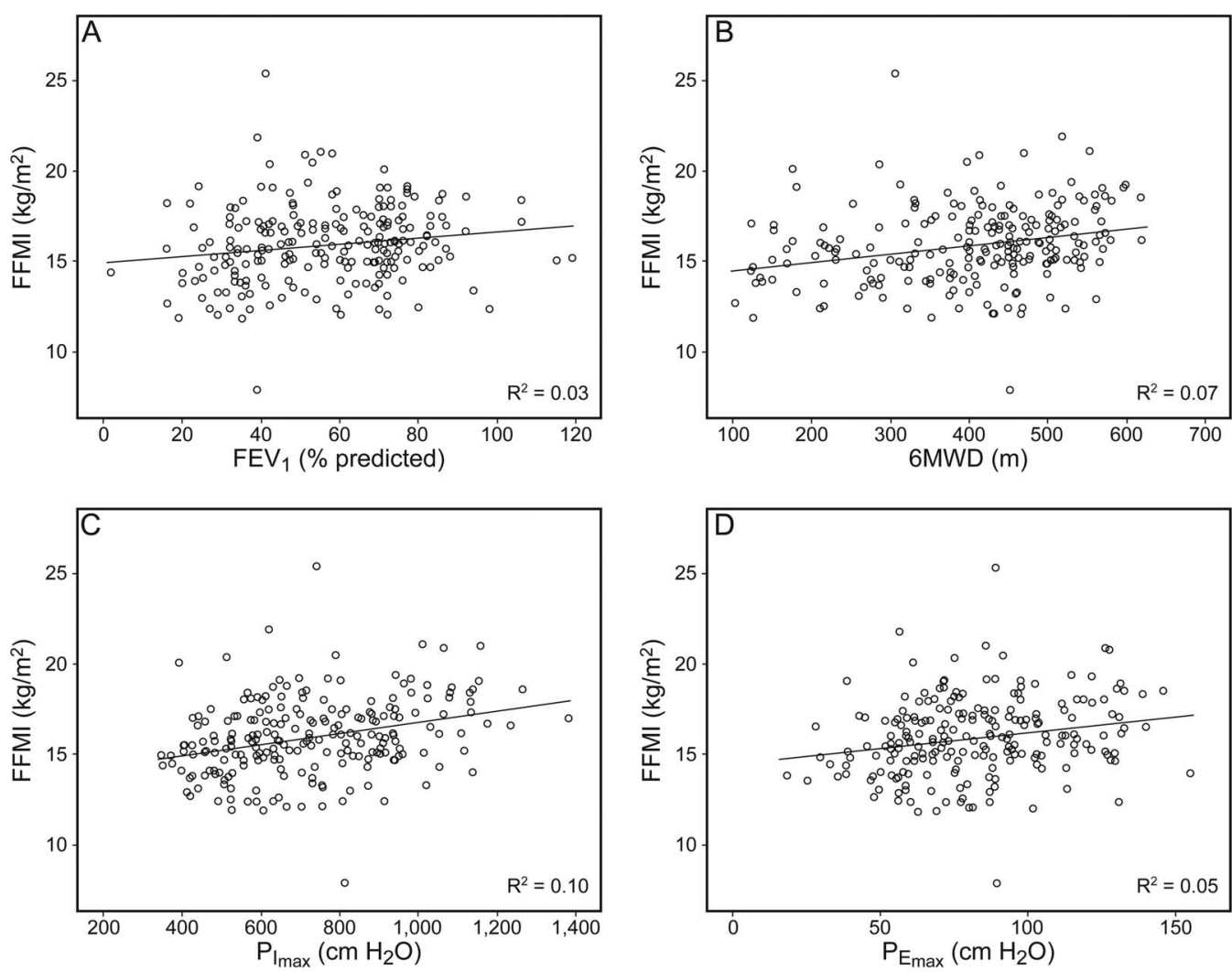

Fig. 1. Correlation between the fat-free mass index (FFMI) in all study subjects with percent-of-predicted $\mathrm{FEV}_{1}(\mathrm{r}=0.17, P=.01)(\mathrm{A}), 6$-min walk test distance (6MWD) $(r=0.26, P<.001)(B)$, maximal inspiratory pressure $\left(P_{\text {Imax }}\right)(r=0.32, P<.001)(C)$ and maximal expiratory pressure $\left(P_{E \max }\right)(r=0.23, P<.001)(D)$.

Table 4. Baseline Characteristics Categorized by COPD Stages

\begin{tabular}{|c|c|c|c|c|c|}
\hline Characteristics & Group A $(n=44)(19 \%)$ & Group B $(n=34)(14 \%)$ & Group C $(n=51)(22 \%)$ & Group D $(n=106)(45 \%)$ & $P$ \\
\hline Age, y & $65.4 \pm 9.7$ & $67.8 \pm 13.9$ & $64.9 \pm 10.0$ & $70.8 \pm 9.5$ & .002 \\
\hline FFMI, $\mathrm{kg} / \mathrm{m}^{2}$ & $16.38 \pm 1.95$ & $16.41 \pm 2.17$ & $16.63 \pm 2.08$ & $15.26 \pm 1.98$ & $<.001$ \\
\hline Males & $16.7 \pm 2.0$ & $16.7 \pm 2.2$ & $16.7 \pm 2.3$ & $15.4 \pm 2.2$ & .001 \\
\hline Females & $15.3 \pm 1.5$ & $15.4 \pm 1.7$ & $16.3 \pm 1.3$ & $14.6 \pm 1.6$ & .040 \\
\hline $\mathrm{FEV}_{1}, \mathrm{~L}$ & $1.88 \pm 0.55$ & $1.57 \pm 0.41$ & $1.32 \pm 0.45$ & $0.99 \pm 0.42$ & $<.001$ \\
\hline $\mathrm{FEV}_{1} / \mathrm{FVC}$ & $60.28 \pm 9.16$ & $59.05 \pm 9.93$ & $54.60 \pm 12.56$ & $47.22 \pm 11.76$ & $<.001$ \\
\hline 6MWD, m & $488.55 \pm 73.40$ & $428.76 \pm 111.99$ & $463.71 \pm 78.24$ & $331.98 \pm 116.68$ & $<.001$ \\
\hline MMRC & $0.36 \pm 0.49$ & $2.35 \pm 0.54$ & $0.78 \pm 0.42$ & $2.93 \pm 0.75$ & $<.001$ \\
\hline $\mathrm{P}_{\text {Imax }}, \mathrm{cm} \mathrm{H}_{2} \mathrm{O}$ & $84.66 \pm 22.24$ & $83.59 \pm 22.97$ & $77.87 \pm 19.38$ & $64.34 \pm 18.95$ & $<.001$ \\
\hline $\mathrm{P}_{\text {Emax }}, \mathrm{cm} \mathrm{H}_{2} \mathrm{O}$ & $96.17 \pm 25.86$ & $93.23 \pm 27.03$ & $87.8 \pm 25.69$ & $73.88 \pm 24.92$ & $<.001$ \\
\hline \multicolumn{6}{|c|}{$\begin{array}{l}N=235 . \text { Data are mean } \pm \text { SD. } \\
\text { FFMI }=\text { fat-free mass index } \\
6 \text { MWD }=6 \text {-min walk distance } \\
\text { MMRC = modified Medical Research Council dyspnea scale } \\
\text { P Imax }=\text { maximal inspiratory pressure }_{\mathrm{P}_{\text {Emax }}=\text { maximal expiratory pressure }}\end{array}$} \\
\hline
\end{tabular}

estingly, the FFMI was lowest in Group D, and both male and female subjects met the criterion for malnutrition. This trend probably reflects a variety of pathologic factors, including an increased frequency of exacerbations, worsened pulmonary function status, protracted and progres- sive disease, chronic oxidative stress, inflammatory stimulation, increased consumption of skeletal muscle protein, pulmonary hypofunction due to advanced COPD, and decreased food intake of food resulting in insufficient energy intake. ${ }^{14,29}$ 
Table 5. Levels of Fat-Free Mass Index for Different Potential Explanatory Variables by Subject Category

\begin{tabular}{|c|c|c|}
\hline & $\mathrm{FFMI} \pm \mathrm{SD}, \mathrm{kg} / \mathrm{m}^{2}$ & $P$ \\
\hline Age, y & & $<.001$ \\
\hline$\leq 60$ & $16.99 \pm 2.23$ & \\
\hline$>60$ & $15.67 \pm 1.99$ & \\
\hline Exacerbations & & .02 \\
\hline$<2$ & $16.24 \pm 2.33$ & \\
\hline$\geq 2$ & $15.59 \pm 1.77$ & \\
\hline GOLD status & & .01 \\
\hline $\mathrm{I}\left(\mathrm{FEV}_{1}>80\right)$ & $16.05 \pm 1.71$ & \\
\hline II $\left(\mathrm{FEV}_{1} 50-80\right)$ & $16.37 \pm 1.96$ & \\
\hline II $\left(\mathrm{FEV}_{1} 30-50\right)$ & $15.71 \pm 2.28$ & \\
\hline IV $\left(\mathrm{FEV}_{1} 0-30\right)$ & $15.02 \pm 2.09$ & \\
\hline MMRC & & $<.001$ \\
\hline$<2$ & $16.51 \pm 2.02$ & \\
\hline$\geq 2$ & $15.54 \pm 2.08$ & \\
\hline 6MWD, m & & .01 \\
\hline$\geq 350$ & $16.16 \pm 2.14$ & \\
\hline $259-349$ & $15.44 \pm 2.03$ & \\
\hline $150-258$ & $15.61 \pm 1.79$ & \\
\hline$\leq 149$ & $14.16 \pm 1.45$ & \\
\hline \multicolumn{3}{|l|}{$\mathrm{P}_{\text {Imax }}, \mathrm{cm} \mathrm{H}_{2} \mathrm{O}$} \\
\hline Female & & .03 \\
\hline$\geq 50$ & $15.77 \pm 1.55$ & \\
\hline$<50$ & $14.78 \pm 1.54$ & \\
\hline Male & & .02 \\
\hline$\geq 75$ & $16.58 \pm 2.19$ & \\
\hline$<75$ & $15.80 \pm 2.14$ & \\
\hline \multicolumn{3}{|l|}{$\mathrm{P}_{\text {Emax }}, \mathrm{cm} \mathrm{H}_{2} \mathrm{O}$} \\
\hline Female & & .12 \\
\hline$\geq 80$ & $15.56 \pm 1.63$ & \\
\hline$<80$ & $14.85 \pm 1.53$ & \\
\hline Male & & .02 \\
\hline$\geq 100$ & $16.53 \pm 2.32$ & \\
\hline$<100$ & $15.78 \pm 2.01$ & \\
\hline $\begin{array}{l}\text { FFMI }=\text { fat-free mass inde } \\
\text { GOLD }=\text { Global Initiative } \\
6 \mathrm{MWD}=6 \text {-min walk dist } \\
\text { MMRC = modified Medic } \\
\mathrm{P}_{\text {Imax }}=\text { maximal inspirator } \\
\mathrm{P}_{\text {Emax }}=\text { maximal expirator }\end{array}$ & $\begin{array}{l}\text { bstructive Lung Disease } \\
\text { puncil dyspnea scale }\end{array}$ & \\
\hline
\end{tabular}

Y1lmaz et al $^{30}$ divided 65 stable subjects with COPD into a low-FFMI group and a normal group. Their results showed that subjects with low FFMI had significantly anthropometric measurements and body composition compared with those with normal FFMI; however, they did not evaluate daily exercise capacity. The FFMI is an important predictor of exercise capacity. FFMI is positively correlated with the 6MWD, as shown in the present results, since malnourished COPD patients are particularly prone to exercise intolerance due to skeletal muscular cell atrophy. ${ }^{31}$ FFMI also reflects the muscle mass more accurately than other indices. ${ }^{32}$ Using radiation technology, Bernard et $\mathrm{al}^{33}$ found that the cross-sectional area of the quadriceps
Table 6. Multiple Linear Regression Analysis with FFMI as the Dependent Variable

\begin{tabular}{lcccc}
\hline \hline Variables & $\beta$ & SE & $95 \%$ CI & $P$ \\
\hline $\mathrm{P}_{\text {Imax }}$ & 0.33 & 0.014 & $0.007-0.057$ & .01 \\
Age & -0.166 & 0.013 & 0.061 to -0.005 & .02 \\
& & & & \\
$\begin{array}{l}\beta=\text { estimated coefficient } \\
\mathrm{P}_{\text {Imax }}=\text { maximal inspiratory pressure } \\
\mathrm{SE}=\text { standard error }\end{array}$ & & & \\
\hline
\end{tabular}

femoris muscle decreased, and the muscle strength declined 20-30\% compared with normal weight subjects. However, the relationship between exercise capacity and FFMI has not been completely elucidated, and it is unknown whether decreased muscle mass alone causes the decline in exercise capacity or whether a multifactorial mechanism is responsible. Potentially, decreased lung function, ${ }^{14}$ progressive dyspnea, ${ }^{34}$ and systemic inflammation ${ }^{12}$ may all help decrease mobility and activity, resulting in muscular atrophy due to disuse of the lower limbs and, ultimately, a decline in the exercise capacity. Similar to previous findings, ${ }^{35}$ the present results show that the exercise capacity of subjects in Group D decreased more than observed in the remaining 3 groups. Notably, prior studies found that early nutritional intervention and exercise training helped to improve the nutritional status and exercise capacity of subjects with COPD. ${ }^{36,37}$

Hyperinflation in COPD increases the end-expiratory gas volume, which displaces the diaphragm into an unsatisfactory position on the length-tension curve. ${ }^{38}$ Consequently, muscle strength is decreased. Decreased respiratory muscle strength is common in subjects with COPD and is strongly correlated with dyspnea. ${ }^{39}$ One study found that the decline in muscle mass can aggravate dyspnea and interfere with the quality of life. ${ }^{40}$ Sabino et $\mathrm{al}^{41}$ reported that respiratory muscle function in subjects with severe COPD was better in those with a higher FFMI than in underweight subjects. This was attributed to the difference in skeletal muscle mass, which is the main component of mat-free mass and dictates the respiratory muscle function. Our study also found that the FFMI was positively correlated with the respiratory muscle strength and negatively correlated with MMRC. However, Weekes et $\mathrm{al}^{42}$ found that subjects who gained weight after 6 months of dietary intervention did not experience an improvement in respiratory muscle function. In contrast, van Wetering et $\mathrm{al}^{36}$ found that the respiratory and periphery muscle strength increased after subjects received nutritional intervention combined with exercise training for 4 months. This result highlights the need to combine nutritional supplementation and exercise rehabilitation training to increase skeletal mass and enhance respiratory muscle function during pulmonary rehabilitation. 


\section{Fat-Free Mass IndeX IN COPD}

We found that FFMI was positively correlated with the severity of lung dysfunction in subjects with COPD. The $\mathrm{FEV}_{1}$ in subjects with a normal FFMI was larger than in subjects with an abnormal FFMI, indicating that malnutrition was associated with impaired lung function. Consistent with our findings, Krzystek-Korpacka et al ${ }^{43}$ found that the $\mathrm{FEV}_{1}$ and percent-of-predicted $\mathrm{FEV}_{1}$ decreased more significantly in malnourished subjects with COPD than in nourished subjects. These findings may reflect skeletal muscle apoptosis caused by inflammation and increased oxidative stress. ${ }^{44}$

Similar to previous studies, we found that frequent exacerbations of COPD led to an apparent decrease in the FFMI. ${ }^{45,46}$ Patients experiencing exacerbation of COPD are prone to weight loss due to the imbalance between dietary intake and energy expenditure. ${ }^{47}$ Difficulty eating and decreased appetite caused by fatigue and dyspnea decrease the dietary intake. In addition, oxygen consumption during ventilation rises due to an increase in the elastic and resistive work of breathing, metabolic effects of theophyllines and $\beta_{2}$ agonists, and proteolysis caused by systemic inflammation. ${ }^{47}$ Nutritional status is correlated with acute COPD exacerbations. Based on the present study findings, improving the nutritional status through nutritional intervention can decrease the frequency of exacerbations and reduce hospitalization costs. ${ }^{36}$

It has been found that the COPD phenotype is associated with clinical and functional variables. ${ }^{24}$ In the present study, we evaluated the FFMI in 4 COPD phenotypes according to CT scans. Our results showed that FFMI was significantly lower in the emphysema-dominant phenotype and mixed phenotype compared with the normal phenotype and airway-dominant phenotype. A previous study 48 showed that severe calorie restriction leads to decreased production of surfactant and a reduction in the number of alveoli with a corresponding increase in alveolar volume and decrease in lung surface area. Another hypothesis suggested emphysema as an autoimmune disease, where protease antiprotease imbalance leads to inflammatory response and therefore tissue destruction is extended from the lungs to whole body soft tissue ${ }^{49}$ However, it remains unclear whether low FFMI contributes to the development of emphysema or whether emphysema leads to the nutritional depletion.

Our results emphasize the significance of FFMI in evaluating the severity of COPD. FFMI is calculated from the biological electrical impedance and is a convenient, inexpensive, and noninvasive method of objectively evaluating the nutritional status of patients. Nutrition supplementation and pulmonary rehabilitation is recommended in Group D subjects based on our findings that the nutritional status, exercise capacity, and respiratory muscle function were lower in the Group D subjects than in the other groups. Our results show that including FFMI within the multidi- mensional evaluation system will affect the distribution of severity in COPD groups. Previous studies have proposed that the BMI is poorly correlated with the severity of $\mathrm{COPD},{ }^{14,16}$ and therefore it may weigh very little in the BODE index ${ }^{50}$ FFMI seems promising as a useful variable replacing BMI in a multidimensional system of COPD evaluation, although more evidence is needed for further validation.

Our study has a few limitations. First, female subjects were fewer due to the relatively low morbidity of COPD in women; in future studies, more women should be enrolled. Second, the enrolled subjects in this study were primarily Asian, and the results should be verified in different racial groups. Third, static lung volume and lung diffusing capacity were not measured in this study, and therefore we did not evaluate the relationship between FFMI and the above variables. Future studies should address this relationship.

\section{Conclusions}

Malnutrition is prevalent in all COPD groups, especially in Group D subjects, highlighting the need to focus on nutritional intervention and pulmonary rehabilitation in this patient group. FFMI is significantly correlated with exercise capacity, dyspnea, respiratory muscle function, and $\mathrm{FEV}_{1}$ and could be used to predict COPD severity.

\section{ACKNOWLEDGMENTS}

We are most grateful to Guangqiao Zeng MD (State Key Laboratory of Respiratory Disease, Guangzhou Medical University, Guangzhou, China) for assistance with medical writing.

\section{REFERENCES}

1. Global Initiative for Chronic Obstructive Lung Disease (GOLD). Global Strategy for the Diagnosis, Management and Prevention of COPD. Updated 2014. http://www.goldcopd.org/. Accessed Oct 16, 2014.

2. Vestbo J, Hurd SS, Agustí AG, Jones PW, Vogelmeier C, Anzueto A, et al. Global strategy for the diagnosis, management, and prevention of chronic obstructive pulmonary disease: GOLD executive summary. Am J Respir Crit Care Med 2013;187(4):347-365.

3. Agustí AG, Noguera A, Sauleda J, Sala E, Pons J, Busquets X. Systemic effects of chronic obstructive pulmonary disease. Eur Respir J 2003;21(2):347-360.

4. Hallin R, Gudmundsson G, Suppli Ulrik C, Nieminen MM, Gislason $\mathrm{T}$, Lindberg E, et al. Nutritional status and long-term mortality in hospitalised patients with chronic obstructive pulmonary disease (COPD). Respir Med 2007;101(9):1954-1960.

5. Wagner PD. Possible mechanisms underlying the development of cachexia in COPD. Eur Respir J 2008;31(3):492-501.

6. Gupta B, Kant S, Mishra R. Subjective global assessment of nutritional status of chronic obstructive pulmonary disease patients on admission. Int J Tuberc Lung Dis 2010;14(4):500-505. 


\section{FAt-Free Mass IndeX IN COPD}

7. Schols AM, Broekhuizen R, Weling-Scheepers CA, Wouters EF. Body composition and mortality in chronic obstructive pulmonary disease. Am J Clin Nutr 2005;82(1):53-59.

8. Mostert R, Goris A, Weling-Scheepers C, Wouters EF, Schols AM. Tissue depletion and health related quality of life in patients with chronic obstructive pulmonary disease. Respir Med 2000;94(9):859867.

9. Schols AM. Nutrition in chronic obstructive pulmonary disease. Curr Opin Pulm Med 2000;6(2):110-115.

10. Grönberg AM, Slinde F, Engström CP, Hulthén L, Larsson S. Dietary problems in patients with severe chronic obstructive pulmonary disease. J Hum Nutr Diet 2005;18(6):445-52.

11. Furutate R, Ishii T, Wakabayashi R, Motegi T, Yamada K, Gemma A, Kida K. Excessive visceral fat accumulation in advanced chronic obstructive pulmonary disease. Int J Chron Obstruct Pulmon Dis 2011;6:423-430.

12. Gan WQ, Man SF, Senthilselvan A, Sin DD. Association between chronic obstructive pulmonary disease and systemic inflammation: a systematic review and a meta-analysis. Thorax 2004;59(7): 574-580.

13. Vestbo J, Prescott E, Almdal T, Dahl M, Nordestgaard BG, Andersen $\mathrm{T}$, et al. Body mass, fat-free body mass, and prognosis in patients with chronic obstructive pulmonary disease from a random population sample: findings from the Copenhagen City Heart Study. Am J Respir Crit Care Med 2006;173(1):79-83.

14. Ischaki E, Papatheodorou G, Gaki E, Papa I, Koulouris N, Loukides $\mathrm{S}$. Body mass and fat-free mass indices in COPD: relation with variables expressing disease severity. Chest 2007;132(1):164-169.

15. Müller U, Jungblut S, Frickmann H, Bargon J. Assessment of body composition of patients with COPD. Eur J Med Res 2006;11(4):146151.

16. Steuten LMG, Creutzberg EC, Vrijhoef HJM, Wouters EF. COPD as a multicomponent disease: inventory of dyspnoea, underweight, obesity and fat free mass depletion in primary care. Prim Care Respir J 2006;15(2):84-91.

17. American Thoracic Society. Standardization of spirometry, 1994 update. Am J Respir Crit Care Med 1995;152(3):1107-1136.

18. American Thoracic Society/European Respiratory Society. ATS/ERS Statement on respiratory muscle testing. Am J Respir Crit Care Med 2002;166(4):518-624

19. Bruschi C, Cerveri I, Zoia MC, Fanfulla F, Fiorentini M, Casali $\mathrm{L}$, et al. Reference values of maximal respiratory mouth pressures: a population-based study. Am Rev Respir Dis 1992;146(3): 790-793.

20. Schols AM, Soeters PB, Dingemans AM, Mostert R, Frantzen PJ, Wouters EF. Prevalence and characteristics of nutritional depletion in patients with stable COPD eligible for pulmonary rehabilitation. Am Rev Respir Dis 1993;147(5):1151-1156.

21. Creutzberg EC, Wouters EF, Mostert R, Weling-Scheepers CA, Schols AM. Efficacy of nutritional supplementation therapy in depleted patients with chronic obstructive pulmonary disease. Nutrition 2003; 19(2):120-127.

22. Bestall JC, Paul EA, Garrod R, Garnham R, Jones PW, Wedzicha JA. Usefulness of the Medical Research Council (MRC) dyspnoea scale as a measure of disability in patients with chronic obstructive pulmonary disease. Thorax 1999;54(7):581-586.

23. ATS Committee on Proficiency Standards for Clinical Pulmonary Function Laboratories. ATS statement: guidelines for the six-minute walk test. Am J Respir Crit Care Med 2002;166(1):111-117.

24. Camiciottoli G, Bigazzi F, Paoletti M, Cestelli L, Lavorini F, Pistolesi M. Pulmonary function and sputum characteristics predict computed tomography phenotype and severity of COPD. Eur Respir J 2013;42(3):626-635.
25. Nakano Y, Muro S, Sakai H, Hirai T, Chin K, Tsukino M, et al. Computed tomographic measurements of airway dimensions and emphysema in smokers: correlation with lung function. Am J Respir Crit Care Med 2000;162(3 Pt 1):1102-1108.

26. Vermeeren MA, Creutzberg EC, Schols AM, Postma DS, Pieters WR, Roldaan AC, et al. Prevalence of nutritional depletion in a large out-patient population of patients with COPD. Respir Med 2006; 100(8):1349-1355.

27. Nordén J, Grönberg AM, Bosaeus I, Forslund HB, Hulthén L, Rothenberg E, et al. Nutrition impact symptoms and body composition in patients with COPD. Eur J Clin Nutr 2015;69(2):256261.

28. Ko GT, Tang J, Chan JC, Sung R, Wu MM, Wai HP, Chen R. Lower BMI cut-off value to define obesity in Hong Kong Chinese: an analysis based on body fat assessment by bioelectrical impedance. Br J Nutr 2001;85(2):239-242.

29. Girón R, Matesanz C, García-Río F, de Santiago E, Mancha A, Rodríguez-Salvanés F, Ancochea J. Nutritional state during COPD exacerbation: clinical and prognostic implications. Ann Nutr Metab 2009;54(1):52-58.

30. Yılmaz D, Çapan N, Canbakan S, Besler HT. Dietary intake of patients with moderate to severe COPD in relation to fat-free mass index: a cross-sectional study. Nutr J 2015;14:35.

31. Agustí AG, Sauleda J, Miralles C, Gomez C, Togores B, Sala E, et al. Skeletal muscle apoptosis and weight loss in chronic obstructive pulmonary disease. Am J Respir Crit Care Med 2002;166(4): 485-459.

32. Rutten EP, Spruit MA, Wouters EF. Critical view on diagnosing muscle wasting by single-frequency bio-electrical impedance in COPD. Respir Med 2010;104(1):91-98.

33. Bernard S, LeBlanc P, Whittom F, Carrier G, Jobin J, Belleau R, Maltais F. Peripheral muscle weakness in patients with chronic obstructive pulmonary disease. Am J Respir Crit Care Med 1998;158(2): 629-634.

34. Kinsman RA, Yaroush RA, Fernandez E, Dirks JF, Schocket M, Fukuhara J. Symptoms and experiences in chronic bronchitis and emphysema. Chest 1983;83(5):755-761.

35. Barusso MS, Gianjoppe-Santos J, Basso-Vanelli RP, Regueiro EM, Panin JC, Di Lorenzo VA. Limitation of activities of daily living and quality of life based on COPD combined classification. Respir Care 2015;60(3):388-398.

36. van Wetering CR, Hoogendoorn M, Broekhuizen R, Geraerts-Keeris GJ, De Munck DR, Rutten-van MM, et al. Efficacy and costs of nutritional rehabilitation in muscle-wasted patients with chronic obstructive pulmonary disease in a community-based setting: a prespecified subgroup analysis of the INTERCOM trial. J Am Med Dir Assoc. 2010;11(3):179-187.

37. Spruit MA, Singh SJ, Garvey C, ZuWallack R, Nici L, Rochester C, et al. An official American Thoracic Society/European Respiratory Society statement: key concepts and advances in pulmonary rehabilitation. Am J Respir Crit Care Med 2013;188(8):e13-e64.

38. Similowski T, Yan S, Gauthier AP, Macklem PT, Bellemare F. Contractile properties of the human diaphragm during chronic hyperinflation. N Engl J Med 1991;325(13):917-923.

39. Hamilton AL, Killian KJ, Summers E, Jones NL. Muscle strength, symptom intensity, and exercise capacity in patients with cardiorespiratory disorders. Am J Respir Crit Care Med 1995;152(6 Pt 1): 2021-2031.

40. Shoup R, Dalsky G, Warner S, Davies M, Connors M, Khan M, et al. Body composition and health-related quality of life in patients with obstructive airways disease. Eur Respir J 1997;10(7): 1576-1580.

41. Sabino PG, Silva BM, Brunetto AF. Nutritional status is related to fat-free mass, exercise capacity and inspiratory strength in severe 


\section{Fat-Free Mass Index in COPD}

chronic obstructive pulmonary disease patients. Clinics 2010;65(6): 599-605.

42. Weekes CE, Emery PW, Elia M. Dietary counselling and food fortification in stable COPD: a randomised trial. Thorax 2009; 64(4):326-331.

43. Krzystek-Korpacka M, Matusiewicz M, Diakowska D, Grabowski K, Neubauer K, Kustrzeba-Wojcicka I, et al. Respiratory insufficiency related to COPD accelerates systemic inflammation, undernutrition, and angiogenesis in esophageal malignancies. Exp Oncol 2008;30(1):75-80.

44. Plataki M, Tzortzaki E, Rytila P, Demosthenes M, Koutsopoulos A, Siafakas NM. Apoptotic mechanisms in the pathogenesis of COPD. Int J Chron Obstruct Pulmon Dis 2006;1(2):161-171.

45. Hallin R, Koivisto-Hursti UK, Lindberg E, Janson C. Nutritional status, dietary energy intake and the risk of exacerbations in patients with chronic obstructive pulmonary disease (COPD). Respir Med 2006;100(3):561-567.
46. Dolan S, Varkey B. Prognostic factors in chronic obstructive pulmonary disease. Curr Opin Pulm Med 2005;11(2):149-152.

47. Vermeeren MA, Schols AM, Wouters EF. Effects of an acute exacerbation on nutritional and metabolic profile of patients with COPD. Eur Respir J 1997;10(10):2264-2269.

48. Harkema JR, Mauderly JL, Gregory RE, Pickrell JA. A comparison of starvation and elastase models of emphysema in the rat. Am Rev Respir Dis 1984;129(4):584-591.

49. Rutten EP, Grydeland TB, Pillai SG, Wagers S, Dirksen A, Coxson HO, et al. Quantitative CT: associations between emphysema, airway wall thickness and body composition in COPD. Pulm Med 2011;2011:419328.

50. Celli BR, Cote CG, Marin JM, Casanova C, Montes de Oca M, Mendez RA, et al. The body-mass index, airflow obstruction, dyspnea, and exercise capacity index in chronic obstructive pulmonary disease. N Engl J Med 2004;350(10):1005-1012. 